http://jmscr.igmpublication.org/home/ ISSN (e)-2347-176x ISSN (p) 2455-0450 crossref DOI: https://dx.doi.org/10.18535/jmscr/v8i1.74

\title{
Efficacy of Rifaximin in patients with Irritable Bowel Syndrome and its Comparison with Previous Drugs: A Retrospective Study
}

\author{
Authors \\ Sangeeta Yadav ${ }^{1}$ Omkar Singh ${ }^{2}$, Manoj Kumar $^{3}$, Ashish Gautam ${ }^{4}$ \\ ${ }^{1}$ Tutor, Autonomous State Medical College, Firozabad \\ ${ }^{2}$ Assistant Professor, Autonomous State Medical College, Firozabad \\ ${ }^{3}$ Associate Professor, Autonomous State Medical College, Firozabad \\ ${ }^{4}$ Associate Professor, SN Medical College, Agra
}

\begin{abstract}
Irritable bowel syndrome often becomes a headache for the patient as well as doctor and till date no drug has proven to be $100 \%$ effective in managing these patients. We studied Rifaximin, one of the latest drug for the management of this disorder and compared it with drugs previously used. This study, a combination of retrospective as well as prospective showed that Rifaximin has the most satisfactory results in these patients, however the results were not sustained as with other drugs.
\end{abstract}

\section{Introduction}

I.B.S. is a disorder that leads to abdominal pain and cramping and changes in bowel movements ${ }^{1}$ and other symptoms in the absence of any organic cause $^{2}$ or detectable structural abnormality. The IBS is one of the most common chronic medical conditions, yet its cause is unknown. It is a source of chronic pain, fatigue, and other symptoms $s^{3,4}$ anxiety, depression ${ }^{5,6}$ which may lead to suicide ${ }^{7}$. Proposed factors for suicide are hopelessness and poor quality of services ${ }^{8,9}$.Patients with I.B.S. fall into two groups. ${ }^{10}$

- Most commonly, patients have abdominal pain associated with altered bowel habits that consist of constipation, diarrhoea, or both.

- In second group, the patients have painless diarrhoea. Painless diarrhoea does not strictly fulfil the Rome-II criteria to be classified as I.B.S.
A large number of drugs have been used for the treatment of IBS till date but none of them has proved to be successful. We studied the effect of Rifaximin in these patients and compared its effect with the drugs previously used. Rifaximin is a semisynthetic antibiotic used for treating traveler's diarrhoea ${ }^{11} \&$ hepatic encephalopathy.

\section{Material and Methods \\ Inclusion Criteria}

Patients who fulfill the ROME 3 Criteria for diagnosis of IBS-D, or Patients attending the OPD having complaints suggestive of IBS-D and did not respond with oral anti-amoebic and gut specific antibiotics, or Patients previously labeled IBS-D after essential investigations and did not respond with previous treatment and between 20 to 50 years of age were included in the study. 


\section{Exclusion Criteria}

Patient of IBS-C, IBS-M and IBS-U subtype ,those who were taking Theophylline, ATT, narcotics, alosetron, lubiprostone, warfarin, antipsychotics, antispasmodic, antidiarrhoeal, probiotics. Any gut specific antibiotic and Rifaximin patients with Underlying co morbid conditions that can alter study results like Diabetes mellitus, thyroid dysfunction, HIV, Chronic kidney disease, Chronic liver disease, Abdominal tuberculosis and previous bowel resection or abdominal surgery (except cholecystectomy, appendectomy and pelvic organ surgery or cesarean section).

\section{Study Type}

A Hospital based retrospective study with prospective comparative analysis was conducted. Patients who were known case of irritable bowel syndrome attending medicine OPD to consult for present symptoms were enrolled for the study. After detailed evaluation of the previous medical records and confirmation of diagnosis of irritable bowel syndrome, its subtype were categorised. Further investigations to substantiate the diagnosis were done if required. Patients who fulfill the inclusion criteria were asked to bring previous treatment records. All the drugs and non pharmacological measures taken by the patient in past pertaining to the irritable bowel syndrome were recorded. Patients were further asked to stop all previous medications and a recommended dose of Rifaximin i.e. $400 \mathrm{mg}$ TID for 10 days was given.

\section{Study Visits}

Patient were called on $10^{\text {th }}, 40^{\text {th }}, 60^{\text {th }}, 75^{\text {th }}$ and $100^{\text {th }}$ day (end of study day for subject) after completion of treatment duration.

\section{Primary Efficacy Evaluaton Period}

Patients were observed for positive response from $10^{\text {th }}$ to $20^{\text {th }}$ day after initiation of treatment day.

\section{Responses}

Patients response was recorded on the same format as done for previous medications.

\section{Follow Up}

Patients responded with 2 or 3 on response score were followed for 100 days at definite intervals.

\section{Recording Response}

\begin{tabular}{|l|c|}
\hline $\begin{array}{l}\text { Level Of Satisfaction } \\
\text { With Rifaximin }\end{array}$ & Not satisfied \\
\hline 0 & $\begin{array}{c}\text { Partially satisfied; but less than } \\
\text { other medications }\end{array}$ \\
\hline 1 & $\begin{array}{c}\text { Partially satisfied; equal to other } \\
\text { medications }\end{array}$ \\
\hline 2 & $\begin{array}{c}\text { Partially satisfied; more then } \\
\text { previous treatment }\end{array}$ \\
\hline 3 & $\begin{array}{c}\text { Complete but ill-sustained } \\
\text { satisfaction }\end{array}$ \\
\hline 4 & Complete and sustained response \\
\hline 5 & \\
\hline
\end{tabular}

\section{Results}

Table 1: Distribution of Study Group According to Age Group and IBS Subtype

\begin{tabular}{|l|c|c|c|}
\hline $\begin{array}{l}\text { AGE } \\
\text { DISTRIBUTION } \\
\text { (in Years) }\end{array}$ & $\begin{array}{c}\text { I.B.S. } \\
\text { Subtype } \\
\text { Diarrhoea } \\
\text { Predominant }\end{array}$ & $\begin{array}{c}\text { I.B.S. } \\
\text { Subtype } \\
\text { Mixed }\end{array}$ & Total \\
\hline $0-20$ & 4 & 3 & 7 \\
\hline $21-30$ & 19 & 7 & 26 \\
\hline $31-40$ & 9 & 6 & 15 \\
\hline $41-50$ & 1 & 5 & 6 \\
\hline$>50$ & 2 & 1 & 3 \\
\hline
\end{tabular}

In our study, total number of patients were 57 in which most of the patients were seen in the age group 21 - 40. Mean Age of the group was 31.16 years. Among all patients $35(61.40 \%)$ were of IBS Subtype Diarrhoea Predominant and 22 (38.60 \%) were of IBS Subtype Mixed. So Diarrhoea Predominant IBS Subtype is more common than Mixed type.

Table 2: Distribution of Study group According to sex and level of Satisfaction with Rifaximin

\begin{tabular}{|l|c|c|}
\hline $\begin{array}{l}\text { LEVEL OF SATISFACTION } \\
\text { WITH RIFAXIMIN : }\end{array}$ & MALE & FEMALE \\
\hline 0 & 3 & 1 \\
\hline 1 & 4 & 1 \\
\hline 2 & 6 & 7 \\
\hline 3 & 5 & 4 \\
\hline 4 & 12 & 11 \\
\hline 5 & 2 & 1 \\
\hline
\end{tabular}


Table 3- Distribution of study group According to I. B. S. Subtype and level of Satisfaction with Rifaximin

\begin{tabular}{|l|c|c|}
\hline $\begin{array}{l}\text { Level Of Satisfaction } \\
\text { With Rifaximin }\end{array}$ & $\begin{array}{c}\text { I. B. S. SUBTYPE - } \\
\text { Diarrhoea Predominant }\end{array}$ & $\begin{array}{c}\text { I. B. S. SUBTYPE } \\
\text { - Mixed }\end{array}$ \\
\hline 0 & 2 & 2 \\
\hline 1 & 1 & 4 \\
\hline 2 & 6 & 7 \\
\hline 3 & 4 & 5 \\
\hline 4 & 19 & 4 \\
\hline 5 & 3 & 0 \\
\hline
\end{tabular}

Table 4 - Distribution of study group According to level of Satisfaction with Rifaximin at Different Points of the Study

\begin{tabular}{|l|c|c|c|c|c|}
\hline $\begin{array}{l}\text { Level } \\
\text { Satisfaction with } \\
\text { RIFAXIMIN }\end{array}$ & $\begin{array}{c}\text { At 10 th Day } \\
\text { (Number of } \\
\text { Patients) }\end{array}$ & $\begin{array}{c}\text { At 40th Day } \\
\text { (Number of } \\
\text { Patients) }\end{array}$ & $\begin{array}{c}\text { At 60th Day } \\
\text { (Number of } \\
\text { Patients) }\end{array}$ & $\begin{array}{c}\text { At 75th DAY } \\
\text { (Number of } \\
\text { Patients) }\end{array}$ & $\begin{array}{c}\text { At 100th Day } \\
\text { (Number of } \\
\text { Patients) }\end{array}$ \\
\hline 0 & 1 & 2 & 5 & 8 & 20 \\
\hline 1 & 3 & 7 & 8 & 11 & 13 \\
\hline 2 & 7 & 8 & 19 & 19 & 10 \\
\hline 3 & 19 & 20 & 15 & 13 & 11 \\
\hline 4 & 8 & 20 & 10 & 6 & 3 \\
\hline 5 & 19 & 0 & 0 & 0 & 0 \\
\hline
\end{tabular}

Most of the patients were very much satisfied with Rifaximin at the 10th day of the study. But the level of satisfaction falls progressively as we move to 100th day of the study. So the satisfaction with Rifaximin is good but not sustained

Table 5 : Average Satisfaction with Rifaximin

\begin{tabular}{|l|c|}
\hline STUDY DAYS & AVERAGE SATISFACTION with RIFAXIMIN \\
\hline 10 & 3.52 \\
\hline 40 & 2.85 \\
\hline 60 & 2.29 \\
\hline 75 & 1.96 \\
\hline 100 & 1.36 \\
\hline
\end{tabular}

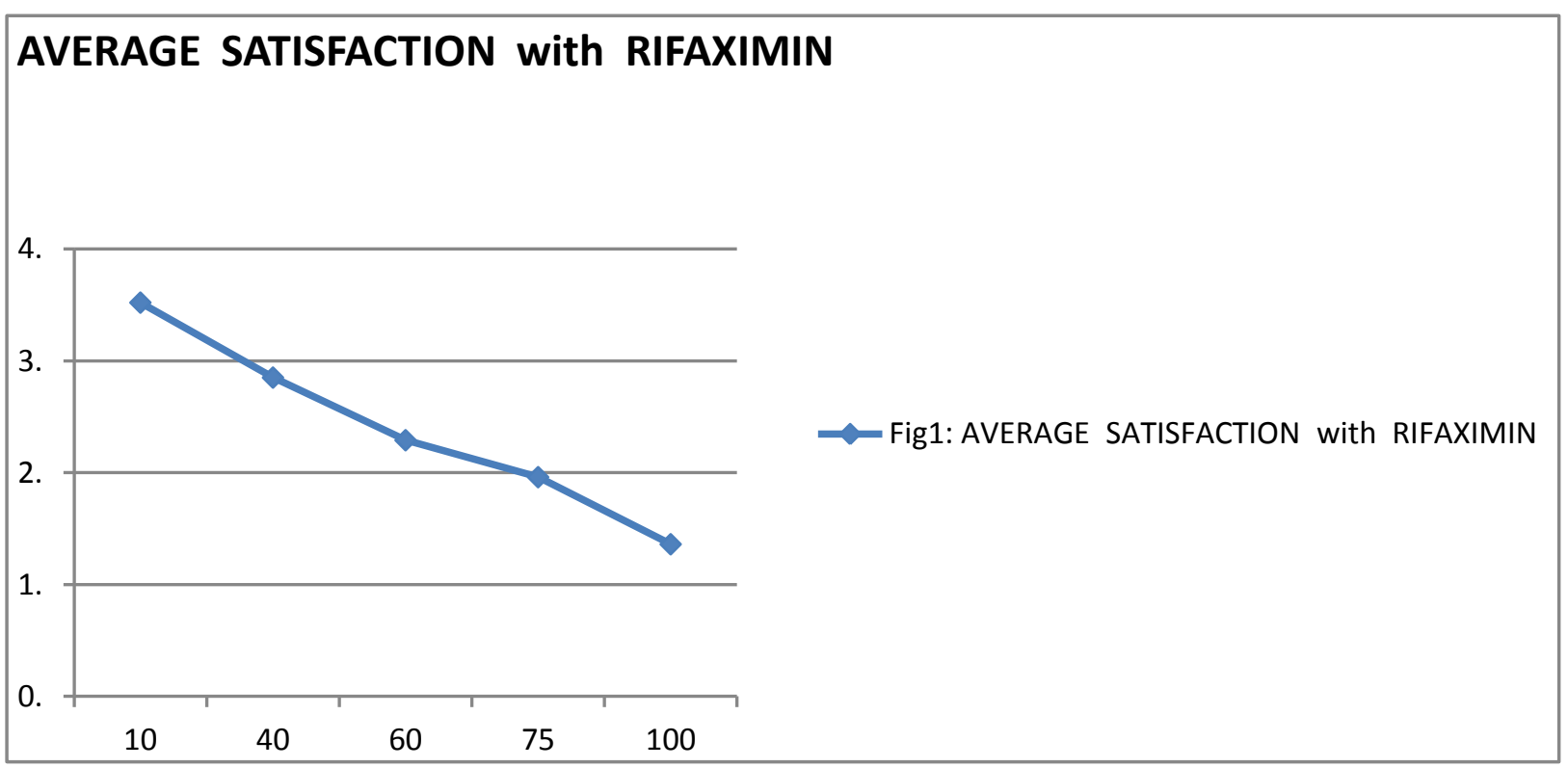

The average level of satisfaction with Rifaximin was 3.52 at the beginning of the study which Shows that the Effect of Rifaximin is Good but gradually fall to 1.36 at the end of the study. IT not Sustained. 


\section{JMSCR Vol||08||Issue||01||Page 470-482||January}

Table 6 Average Satisfaction With Different Drugs

\begin{tabular}{|l|c|}
\hline DRUGS & AVERAGE SATISFACTION \\
\hline RIFAXIMIN & 2.89 \\
\hline LOPERAMIDE & 2.24 \\
\hline PSYLLIUM HUSK & 2.03 \\
\hline SMOOTH MUSCLE RELAXANT & 1.93 \\
\hline TRICYCLIC ANTIDEPRESSANT & 2 \\
\hline SSRIS & 1.26 \\
\hline PROBIOTICS & 1.57 \\
\hline FQ+METROGYL & 2.70 \\
\hline METROGYL & 2.63 \\
\hline PREBIOTICS & 2.12 \\
\hline
\end{tabular}

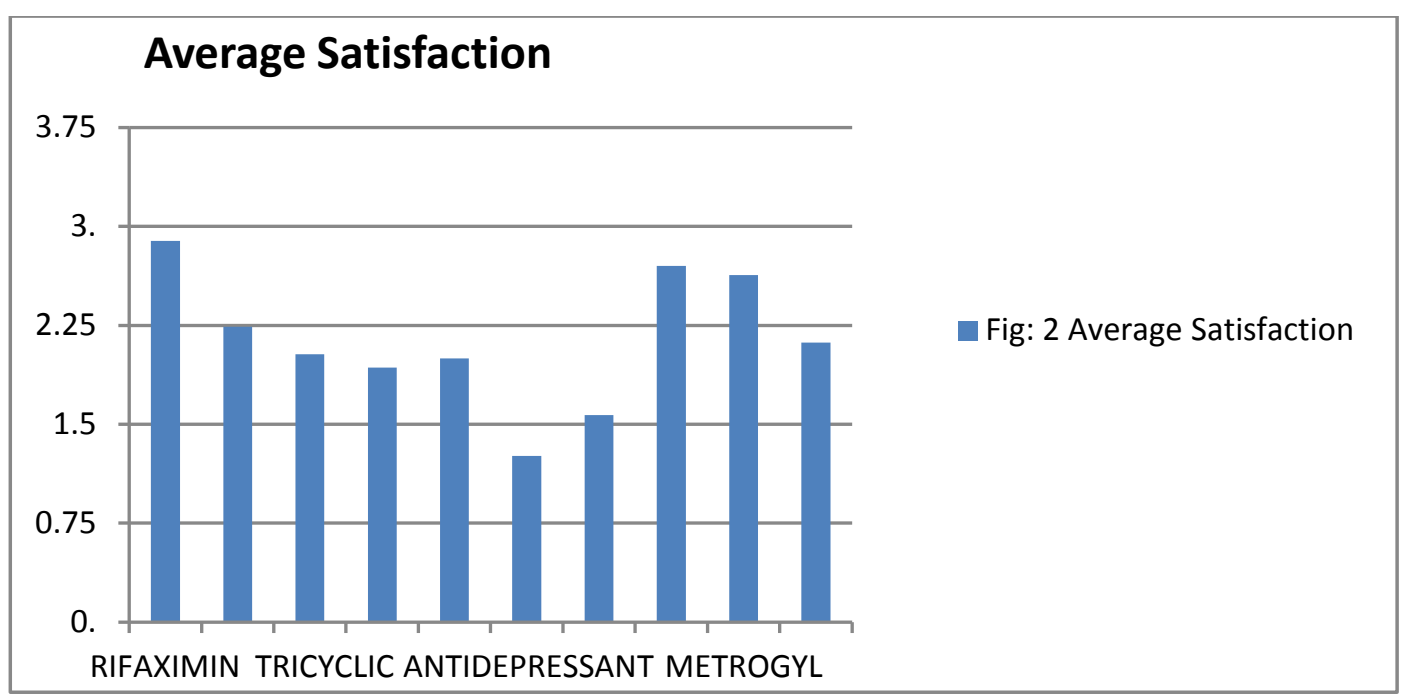

Fig $1 \& 2$ show that the average level of satisfaction for all the drugs prescribed for IBS patients in which RIFAXIMIN has topped the list followed by the combination of FQ + Metrogyl and then Metrogyl alone, while SSRIs came last among this group.

This shows that the use of the antibiotics is relatively more effective in relieving the symptoms of I.B.S. patients than other medicines (loperamide, psyllium husk, smooth muscle relaxants, tricyclic antidepressants, SSRIs, probiotics, prebiotics)

\section{Discussion}

Recurrent gut infection and change in gut flora in IBS and use of antibiotics:

Change in gut flora is one of the strongly proposed mechanism behind the development of IBS - D and IBS - M. Table no. - 6: shows Rifaximin and different medications or measures previously prescribed individually on different patients and their average level of satisfaction. As we can see that RIFAXIMIN has topped the list (with average level ofsatisfaction2.89) followed by the combination of FQ + Metrogyl and then Metrogyl alone, While SSRIs came last (with average level of satisfaction1.26) among this group. From the above observation we can see that the use of the antibiotics isrelatively more effective in relieving the symptoms of I.B.S. patients than other medicines (loperamide, psyllium husk, smooth muscle relaxants, tricyclicantide presents, SSRIs, probiotics, prebiotics). This strongly suggest recurrent gut infections as the possible etiopathogenesis for the development of Irritable Bowel Syndrome. This was also shown in a study done by Scarpellini E et $\mathrm{al}^{12}$ in which they observed that Rifaximin was effective and safe in SIBO treatment and IBS symptoms improvement in childhood.

Satisfaction with Rifaximin at different points of the study:

Table no.5 shows average level of satisfaction with Rifaximin at different points of the study 
which shows that the level of satisfaction with Rifaximin was very high at the beginning of the study but it progressively fall when we move towards the end of the study (100 th day). It shows that the effect of Rifaximin is good but not sustained. The result of this study contradict the result of previous studies done worldwide. Jiang $\mathrm{ZD}$ et $\mathrm{al}^{13}$ (2005) observed that in vitro inhibitory activity of Rifaximin isdirected against Grampositive and Gram-negative, aerobic and anaerobic bacteria. It is effective in the treatment of gastrointestinal infections when given orally because of the high concentration of the drug remaining in the gut lumen. Laboratory investigations have been carried out to assess the in vitro activity of Rifaximin on different bacterial strains isolated from both human and domestic animals. The available data suggest that Rifaximin is active in vitro and in vivo in the treatment of bacterial infection of adults and children. Pimentel $\mathrm{M}$ et $\mathrm{al}^{14}$ observed in their study that among patients who had IBS without constipation, treatment with Rifaximin for 2 weeks provided significant relief of IBS symptoms, bloating, abdominal pain, and loose or watery stools. Schey $\mathrm{R}^{15}$ et al concluded in a study that a 2 -week course of Rifaximin provided significant relief of IBS symptoms, as well as bloating and abdominal pain.

The possible reasons behind contradictory results of our study from previous study results may be:-

1. The studies done previously were from developed countries where incidences of recurrent G.I. infections are very less.

2. Our study is done in a Tropical country where the incidences of recurrent gut infections are very high.

3. Our study group size is very small in comparison to the other studies done worldwide.

\section{IBS Subtypes and sex of the patient}

Our study shows that among Males, Diarrhoea Predominant IBS Subtypeis more common. While among Females Mixed IBS Subtype is slightly more common which is supported by the previous studies. Our study also shows that males are more affected than females which is contradicted by the previous studies. It may be due to the small size of our study. In a study by Sun-Young Lee et $\mathrm{al}^{16}$ out of 253 women and 252 men, $4150.8 \%$ of women were diagnosed as IBS, while $35.8 \%$ of men were diagnosed as IBS ( $p=0.01$ ). With aspect to the IBS subtypes, the diarrhoea-dominant type was more common in men, while constipation dominant or alternating types were more common in women (p\&lt; 0.001). The increased prevalence of IBS in women may be related to psychosocial factors rather than differences in colonic motor function because there is no gender differences in visceral perception.

\section{IBS subtypes and satisfaction with Rifaximin}

Most of the patients of diarrhoea predominant subtype have level of satisfaction 4 with Rifaximin while most of the patients of Mixed subtypehave level of satisfaction 2. So patients of diarrhoea predominant subtypeare more satisfied with Rifaximin than Mixed type.

\section{Sex of the Patient and Satisfaction with Rifaximin}

No difference was found between male and female patients regarding the effect of Rifaximin.

\section{Conclusion}

Prominent reason behind the higher satisfaction rate with antibiotic predominantly Rifaximin and also with others is due to the fact that most of the cases in India are infection related. Rifaximin has been used extensively in IBS disease in the past with successful results. However in India results are of much greater significance as predominant underlying cause of IBS is infection related. More over greater satisfaction was seen with IBS-D type.

\section{References}

1. Schmulson MW, Chang L (1999). "Diagnostic approach to the patient with irritable bowel syndrome". Am. J. Med. 107(5A): 
doi:10.1016/S0002-9343(99)00278-

8.PMID 10588169.

2. Malagelada, JR (2006). "A symptombased approach to making a positive diagnosis of irritable bowel syndrome with constipation". International journal of clinical practice 60(1): 5763. doi:10.1111/j.1368-

5031.2005.00744.x.PMID 16409429.

3. Paré P, Gray J, Lam S et al. (2006). "Health-related quality of life, work productivity, and health care resource utilization of subjects with irritable bowel syndrome: baseline results from LOGIC (Longitudinal Outcomes Study of Gastrointestinal Symptoms in Canada), a naturalistic study". Clinical therapeutics 28 (10): 1726-35; discussion 17101. doi:10.1016/j.clinthera.2006.10.010.PM ID 17157129.

4. Maxion-Bergemann S, Thielecke F, Abel F, Bergemann R (2006). "Costs of irritable bowel syndrome in the UK and US". PharmacoEconomics 24 (1): $21-$ 37.doi:10.2165/00019053-20062401000002.PMID 16445300.

5. "IBS and Depression Connection and Treatments". Webmd.com. Retrieved 2012-10-21.

6. Thabane M, Kottachchi DT, Marshall JK (2007)."Systematic review and metaanalysis: The incidence and prognosis of post-infectious irritable bowel syndrome". Aliment Pharmacol Ther 26 (4): 53544. doi:10.1111/j.13652036.2007.03399.x. PMID 17661757.

7. Vorous, Heather Van (19uu). Eating for I.B.S. Marlowe \& Co..: Marlow \& Co. ISBN 1569246009.

8. Miller, V; Hopkins, L; Whorwell, PJ (2004 Dec). "Suicidal ideation in patients with irritable bowel syndrome.". Clinical gastroenterology and hepatology: the official clinical practice journal of the
American Gastroenterological Association 2 (12): 1064-8. PMID 15625650.

9. Spiegel, B; Schoenfeld, P; Naliboff, B (2007 Jul 15). "Systematic review: the prevalence of suicidal behaviour in patients with chronic abdominal pain and irritable bowelsyndrome.". Alimentary pharmacology \& therapeutics 26 (2): 18393. PMID 17593064.

10. Holten KB, Wetherington A, Bankston L (2003)."Diagnosing the patient with abdominal pain and altered bowel habits: is it irritable bowel syndrome?". Am Fam Physician 67 (10):

2157-62. PMID 12776965

11. DuPont HL, Jiang ZD, Okhuysen PC. A randomized, double-blind, placebocontrolled trial of rifaximin to prevent travelers' diarrhea. Ann Intern Med. 2005 May 17, 142(10):805-12.

12. Scarpellini E, Giorgio V, Gabrielli M, Filoni S, Vitale G, Tortora A, Ojetti V,Gigante G, Fundarò C, Gasbarrini A.Eur Rev Med Pharmacol Sci. 2013 May;17(10):1314-20.

13. Jiang ZD, DuPont HL. Rifaximin: in vitro and in vivo antibacterial activity--a review. Chemotherapy. 2005;51 Suppl 1:67-72.

14. Pimentel M, Lembo A, Chey WD, Zakko S, Ringel Y, Yu J, Mareya SM, Shaw AL, Bortey E, Forbes WP. N Engl J Med. 2011 Jan 6;364(1):22-32. doi: 10.1056/NEJMoa1004409.

15. Schey R, Rao SS. Expert Rev Gastroenterol Hepatol. 2011 Aug;5(4):461-4. doi: 10.1586/egh.11.50.

16. Lee SY, Kim JH, Sung IK, Park HS, Jin CJ, Choe WH, Kwon SY, Lee $\mathrm{CH}$, Choi $\mathrm{KW}$. Irritable bowel syndrome is more common in women regardless of the menstrual phase: a Rome II-based survey. J Korean Med Sci. 2007; 22(5):851-854. doi: 10.3346/jkms.2007.22.5.851. 